\title{
Enhanced Rooting of Kinnikinnick Cuttings using Mycorrhizal Fungi in Rooting Substrate
}

\author{
C.F. Scagel ${ }^{1}$
}

AdDitional INDEX wORds. Glomus intraradices, Laccaria laccata, Arctostaphylos uva-ursi 'Massachusetts', arbuscular mycorrhizal fungi, arbutoid mycorrhizal fungi

Summary. Hardwood cuttings of kinnikinnick (Arctostaphylos uva-ursi 'Massachusetts') were inoculated with three different types of inoculum of mycorrhizal fungi to determine whether addition of mycorrhizal inoculum into the rooting substrate during cutting propagation increases rooting or root growth, or alters the time for rooting. Cuttings, treated or untreated with rooting hormone prior to sticking into the rooting substrate, were inoculated with either inoculum of an arbuscular mycorrhizal fungus (AMF), hyphal inoculum of an arbutoid mycorrhizal fungus (E), or inoculum consisting of colonized root fragments of kinnikinnick $(R)$. Cuttings were placed under mist in a greenhouse with no bottom heat and harvested 35,56 , and 84 days after sticking. Using AMF inoculum in the rooting substrate did not enhance rooting of cuttings, while adding the $\mathrm{R}$ or $\mathrm{E}$ inoculum to the rooting substrate increased root initiation compared to non-inoculated cuttings. Cuttings inoculated with either the $R$ or $\mathrm{E}$ inoculum had greater root initiation than non-inoculated cuttings 56 and 84 days after sticking. When treated with rooting hormone, cuttings inoculated with the $\mathrm{E}$ or $\mathrm{R}$ inoculum had longer roots and a greater root biomass than non-inoculated

U.S. Department of Agriculture, Agricultural Research Service, Horticultural Crops Research Unit, 3420 NW Orchard Avenue, Corvallis, OR, 97330, USA. Tel. 541-738-4063. E-mail: scagelc@onid.orst.edu

The author gratefully acknowledges the technical assistance of Kathleen Eggemeyer, Mary Kate Valentine, Miranda Collins, Lisa Tribbet, and the donation of plant material from Briggs Nursery, Olympia, Washington. Mention of a trademark, proprietary product, orvendor does not constitute a guarantee or warranty of the product by the U.S. Dept. of Agriculture and does not imply its approval to the exclusion of other products or vendors that also may be suitable.

${ }^{1}$ Research Plant Physiologist. 
cuttings. Mycorrhizal colonization of roots was similar or greater when cuttings were inoculated with the $\mathrm{E}$ inoculum than with the $R$ inoculum and application of rooting hormone generally increased root colonization. The use of inoculum composed of root fragments from kinnikinnick during cutting propagation does not appear to be more beneficial than use of hyphal inoculum from a known arbutoid mycorrhizal fungus.

M ycorrhizae are symbiotic associations between plant roots and certain soil fungi that can enhance plant growth and survival through their effects on nutrient and water acquisition (Smith and Read, 1997). The benefits from root colonization by mycorrhizal fungi are thought to be greatest when colonization occurs as early as possible during plant growth (Chang, 1994). In the propagation of plants from cuttings, this means that maximum benefits from mycorrhizal colonization would be obtained if inoculum is present during adventitious root formation.

The addition of mycorrhizal fungi into the rooting substrate during cutting propagation can increase rooting in different plants (Douds et al., 1995; Linderman and Call, 1977; Scagel, 2000, 2001, 2004a, 2004b; Verkade and Hamilton, 1987; Verkade et al., 1988). Although commercially produced inoculum of certain types of mycorrhizal fungi is readily available to horticulturists, the relationship between inoculum type and plant response is unclear.

The rooting of woody stem cuttings at certain stages of development during the year is dependent upon the physiological condition of the stock plant and treatment of the cuttings with rooting hormone. Rooting of kinnickinnick cuttings is sometimes difficult and cuttings appear to root best from hardwood cuttings in early autumn (Górecka, 1979). Attempts to root kinnickinnick cuttings at other times can result in a low percentage of rooted cuttings and poor survival after transplant (Holden, 1975). Kinnickinnick forms a type of mycorrhizal association called "arbutoid" mycorrhizae (EMF). The fungi that form these associations with kinnickinnick roots are generally considered the same fungal species that can also form ectomycorrhizal associations with the roots of several other plant species (Smith and Read, 1997).

Rooting of kinnickinnick cuttings taken during the optimal time for rooting can be increased by addition of mycorrhizal kinnickinnick roots into the rooting substrate of cuttings (Holden, 1978). Linderman and Call (1977) reported that inoculating cuttings of kinnickinnick plants with arbutoid mycorrhizal fungi can increase adventitious rooting at times of the year when cuttings treated only with hormones root poorly. They found that the response of cuttings was highly dependent on the fungal isolate used in their study.

Inoculation of kinnickinnick cuttings with the arbuscular mycorrhizal fungus (AMF), Glomus intraradices, has also been reported to increase rooting (Nelson, 1987). The rooting response of miniature rose (Rosa sp.) cuttings to mycorrhizal fungi has been found to occur without root colonization (Scagel, 2004a). This suggests that some form of signaling occurs between the fungus and the plant stem that triggers an increase in rooting of cuttings. Commercially available inocula of AMF (e.g., G. intraradices and several other fungal species-species composition varies by product) and ectomycorrhizal fungi (that can form arbutoid mycorrhizal associations with kinnickinnick) are available to propagators. Although AMF will not form a mycorrhizal association with kinnickinnick, it is possible that AMF inoculum may be used as a tool to increase rooting of kinnickinnick cuttings, particularly when used on cuttings stuck at a non-optimal time for rooting.

Although separate studies have described the influence of different types of mycorrhizal inoculum on rooting of kinnickinnick, a direct comparison of the effectiveness of different inoculum types on rooting has not been reported. Also, the influence of mycorrhizal inoculum on the rate of rooting has not been reported. The objectives of this study were to determine whether the addition of different types of mycorrhizal inoculum (e.g., AMF, EMF, colonized kinnickinnick root fragments) into the rooting substrate during cutting propagation increases rooting or root growth, and whether inoculation alters the time for rooting of kinnikinnick when cuttings are taken during a season considered a non-optimal time from rooting.

\section{Materials and methods}

Plant material. In late Feb. 1999, rooted tissue culture plantlets of kinnickinnick 'Massachusetts' were obtained from Brigg's Nursery (Olympia, Wash.) and transplanted into 0.64 -L pots $[10.2 \mathrm{~cm}$ (4 inches) diameter, Gage Dura Pot \#GDP400; Gagee Industries, Lake Oswego, Ore.] in a mix of $80 \%$ composted douglas-fir bark (Whitney Farms, Independence, Ore.) and $20 \%$ sphagnum peat (Sunshine Grower Grade White; Sun Grow, Hubbard, Ore.) by volume amended with $5.5 \mathrm{~g} \cdot \mathrm{L}^{-1}\left(5.50 \mathrm{oz} / \mathrm{ft}^{3}\right)$ of a slow release fertilizer (SLR) (Osmocote Plus 15N-4.1P-10K; Scotts Co., Marysville, Ohio) per pot. Equal amounts of fertilizer were mixed into the rooting substrate on a per-pot basis to ensure uniform distribution. Plants were maintained in a greenhouse, with supplemental light (16-h photoperiod), average day/night temperatures of $21^{\circ} \mathrm{C}\left(69.8^{\circ} \mathrm{F}\right)$ day $/ 16^{\circ} \mathrm{C}\left(60.8^{\circ} \mathrm{F}\right)$ night, and watered as needed. Periodic pest control measures were performed as needed and included diflubenzuron for fungus gnats (Bradysiasp.) and Neoseiulus cucumeris predators for thrips (Frankiniella sp.). After 16 weeks, plants were transplanted into cylindrical 3.8-L (1 gal) pots $[19.4 \times 18.1 \mathrm{~cm}$ (7-5/8 $\times 7-1 / 8$ inches); Lerio Corp., Mobile, Ala.] containing a mix of $30 \%$ composted douglas-fir bark, $60 \%$ peat, and $10 \%$ perlite by volume amended with $8 \mathrm{~g} \cdot \mathrm{L}^{-1}\left(8.0 \mathrm{oz} / \mathrm{ft}^{3}\right)$ of SLR per pot and grown outside under ambient conditions in Corvallis, Ore. (lat. $44^{\circ} 59^{\prime} 041$ ' N, long. 12327’217’ W) and watered as needed.

InOcula. Three inocula types were used in the experiment described below. The root inoculum (R) was prepared by removing the roots from 1-year old kinnikinnick plants, washing all potting substrate from roots, then fragmenting roots in a blender at low speed for $3 \mathrm{~min}$. The arbuscular mycorrhizal fungus (AMF) inoculum (A) consisted of Glomus intraradices originally obtained from Native Plants Incorporated, (Salt Lake City) and maintained in pot cultures at the USDA-ARS, Horticultural Crops Research Laboratory in Corvallis, Ore. The fungus was propagated in pot cultures on roots of bunching onion (Allium cepa 'White Lisbon') grown in $(\mathrm{v} / \mathrm{v})$ l Willamette Valley alluvial silt loam: 1 river sand [11 
$\mathrm{mg} \cdot \mathrm{kg}^{-1}$ (ppm) available (Bray) phosphorus $(\mathrm{P}), \mathrm{pH}$ of 6.3 ] for 5 months. Inoculum consisted of a mixture of the soil substrate, extraradical hyphae and spores, and colonized root segments [<2 mm (0.08 inch) long] with a bulk density of $4.74 \mathrm{~g} \cdot \mathrm{cm}^{-3}$. The most probably number (MPN) method (Woomer, 1994) was used to estimate the density of the inoculum which averaged 10 propagules/g (283.5 propagules/oz) of soil substrate. The arbutoid or ectomycorrhizal fungus (EMF) inoculum (E) consisted of Laccaria laccata (identification based on associated sporocarp), isolated from root tips of 1-year-old kinnikinnick plants and maintained on modified Melin-Norkrans (MMN) agar medium (Molina and Palmer, 1982). Cultures for inoculum were grown in sterile culture of liquid MMN media on an orbital shaker at room temperature for $28 \mathrm{~d}$. One day prior to inoculation, hyphae from 16-week-old cultures of the fungus were harvested by filtration and re-suspended in $1 \mathrm{~L}(0.26 \mathrm{gal})$ sterile water and fragmented in a blender at low speed for $3 \mathrm{~min}$. The number of colony forming fragments per volume of water-based inoculum mixture was $79 \mathrm{cfu} / \mathrm{mL}$ based on 10 replicate plates of $1 \mathrm{~mL}$ of inoculum on MMN agar incubated at $21{ }^{\circ} \mathrm{C}$ for $14 \mathrm{~d}$.

EXPERIMENTAL SETUP. On 3 Feb. 2000 , cuttings were removed from the previous year's growth on pot-grown l-year-old kinnikinnick plants. Cuttings were sorted for uniformity (based on fresh weight and length), and were sanitized to disinfect the cutting of potential pathogens by dipping the end of each cutting into $10 \%$ solution of sodium hypochlorite (Dixichlor; DXI Industries, Houston) for $20 \mathrm{~min}$ and then rinsing with water. Cuttings were placed randomly into eight treatment groups: no hormone and no inoculum $(\mathrm{CN})$; hormone treatment and no inoculum $(\mathrm{CH})$; no hormone treatment and root inoculum (RN); hormone treatment and root inoculum $(\mathrm{RH})$; no hormone treatment and AMF inoculum (AN); hormone treatment and AMF inoculum (AH); no hormone treatment and EMF inoculum (EN); and hormone treatment and EMF inoculum (EH). Cuttings that received no hormone treatment ( $\mathrm{CN}, \mathrm{RN}, \mathrm{AN}$, and $\mathrm{EN})$ were stuck directly into 0.64 - L pots containing $80 \%$ perlite and $20 \%$ peat by volume. Cuttings receiving hormone treatment
(CH, $\mathrm{RH}, \mathrm{AH}$, and $\mathrm{EH}$ ) were dipped for $5 \mathrm{~s}$ in $3000 \mathrm{mg} \cdot \mathrm{L}^{-1}(\mathrm{ppm})$ Woods Hormone Solution (1.03\% indol-3butyric acid and $0.66 \%$ l-napthalene acetic acid; Earth Science Products Corp., Wilsonville, Ore.), then stuck into 0.64 - $\mathrm{L}$ pots containing the same perlite-peat mix. Prior to sticking, 2 $\mathrm{g}$ fresh weight of root inoculum was placed directly in the region where the cutting was stuck for cuttings receiving rootinoculum ( $\mathrm{RN}$ and $\mathrm{RH}$ ), and $5 \mathrm{~mL}$ AMF inoculum placed directly in the region where the cutting was stuck for cuttings receiving $\mathrm{AMF}$ inoculum (AN and $\mathrm{AH}$ ). For inoculation with EMF, inoculation treatments were applied immediately after sticking by drenching the rooting substrate at the base of the cutting with $10 \mathrm{~mL}$ of EMF inoculum (EN and $\mathrm{EH})$. Pots were placed on a mist bench in a greenhouse and rooted under intermittent mist with supplemental light ( $16 \mathrm{~h}$ photoperiod) and average day/night temperatures of $21{ }^{\circ} \mathrm{C}$ day $/ 16{ }^{\circ} \mathrm{C}$ night. Misting intervals varied during the experiment and ranged from $10 \mathrm{~s}$ every $30 \mathrm{~min}$ to $10 \mathrm{~s}$ every $2 \mathrm{~h}$. No bottom heat was used during the experiment.

Data collection. Cuttings were removed from the mist bed 35 , 56 , and $84 \mathrm{~d}$ after the start of the experiment, and the number of rooted cuttings per treatment was recorded. At all harvest times, the primary and secondary roots on each cutting were counted, removed from the cutting, and the length of each primary root was measured. Fresh weights were obtained for aboveground portion (region above rooting zone) and new roots on each cutting. A sub-sample of fresh roots was used to determine root colonization. The remainder of the aboveground and root tissues were dried at $60{ }^{\circ} \mathrm{C}$ $\left(140.0^{\circ} \mathrm{F}\right)$, and dry weights were obtained after tissue had reached a constant dry weight (48-60 h). Root colonization in treatment $\mathrm{RN}, \mathrm{RH}$, $\mathrm{EN}$, and $\mathrm{EH}$ was determined on fresh roots by measuring the percentage of root tips that showed external signs of mycorrhizae. Representative roots were examined for internal hyphae for verification of mycorrhizae formation. AMF colonization of roots for treatments $\mathrm{AN}$ and $\mathrm{AH}$ was assessed on $\mathrm{l}-\mathrm{cm}(0.4$ inch $)$ sections of fresh roots after clearing and staining by modified procedures of Phillips and Hayman (1970), replacing lacto-phenol with lacto-glycerin. Percentage of root length with signs of AMF colonization (arbuscular formation) was estimated by the method of Biermann and Linderman (1980).

EXPERIMENTAL DESIGN AND STATISTICAL ANALYSES. The experiment was a $2 \times 4 \times 3$ factorial design with two rooting hormone treatments, four inoculation treatments, and three harvest dates arranged in a randomized block design. Each treatment unit (pot) contained three cuttings (one for each harvest date) replicated two times in each of four blocks ( eight cuttings per treatment per harvest date). Within-block treatment replication was done to provide adequate replication for analysis of survival data. Most data were subjected to three-factor analysis of variance (ANOVA) using the Statistica statistical package (Statsoft, Tulsa, Okla.) with hormone treatment, inoculation treatment, and harvest date as main effects. Plants in treatments $\mathrm{CN}, \mathrm{CH}, \mathrm{AN}$, and $\mathrm{AH}$ showed no evidence of mycorrhizal colonization; therefore, colonization data were subjected to a three-factor ANOVA with two hormone treatments, two inoculation treatments and harvest date as main effects. Dry weight and root colonization, number and size data were square-root transformed prior to analysis to correct for unequal variance and achieve best model fit. Actual data are reported in tables and figures. Where appropriate, Bonferroni test was used to separate treatment means $(P$ $<0.05)$. Relationships between root colonization and root growth variables were assessed using Pearson's correlation coefficient $(r)$.

\section{Results and discussion}

Rooting. Cuttings inoculated with root-fragment inoculum ( $\mathrm{R}$ ) or hyphal inoculum from an arbutoid mycorrhizal fungus (E) generally had a higher percentage of cuttings with roots (rooting) than non-inoculated cuttings $(\mathrm{C})$, while cuttings inoculated with AMF inoculum generally had lower rooting than non-inoculated cuttings (Fig. 1A). At the final harvest, $84 \mathrm{~d}$ after sticking, rooting was similar on non-inoculated cuttings and cuttings inoculated with either the $\mathrm{R}$ or E inoculum. Regardless of inoculation treatment, application of rooting hormone to cuttings increased rooting 56 and $84 \mathrm{~d}$ after sticking (Fig. 1B).

Cuttings inoculated with mycorrhizal fungi root better than non- 
inoculated cuttings, however the influence of mycorrhizal fungi on rooting appears to be specific to the fungus-plant combination and the length of time after cuttings are stuck. When cuttings of rainbow leucothoe (Leucothoe fontanesiana 'Rainbow') were inoculated with different isolates of ericoid mycorrhizal fungi, rooting was greater on cuttings inoculated with two of the three isolates tested than on non-inoculated cuttings early during propagation; however at the end of a 109 -d propagation cycle, inoculation had no influence on the number of rooted cuttings (Scagel, 2004b). Douds et al. (1995) increased rooting of cuttings by adding inoculum of an AMF to the rooting substrate of umbrella-pine (Sciadopitys verticillata), and reported increased survival, callus development, and rooting percentages for cuttings, which usually take up to 6 months to root. With miniature roses, adding AMF inoculum to the rooting substrate increased the percentage of rooted cuttings of cultivars that did not respond to hormone application, and enhanced early rooting for difficult-toroot cultivars (Scagel, 2001).

When AMF inoculum was used with kinnikinnick we did not observe any increase in rooting, while Nelson (1987) reported that adding AMF inoculum into the rooting substrate of kinnikinnick increased rooting of cuttings. Our results may be different from that of Nelson (1987) due to differences in plant material or isolate of AMF used. Although AMF can cause rooting responses in cuttings of known host plants prior to colonization ( $\mathrm{Sca}-$ gel, 2004a), the ability of AMF to cause a similar response in non-host plants may be minimal. A sequence of signaling/recognition events may occur during different stages of plant-AMF interactions, but little is known about these signaling molecules (Roussel et al., 2001). These molecules have been investigated in root-AMF interactions, but not in interactions between stems and AMF. Stem-AMF signaling may not be as specific as the interactions that occur between roots and AMF; however, there may be some specificity in the interaction with regard to host compatibility. The plant's role in the interaction may be a release of general metabolites or carbon dioxide from the end of the cutting. This release, similar to the process of root exudation, may cause a general stimulus that

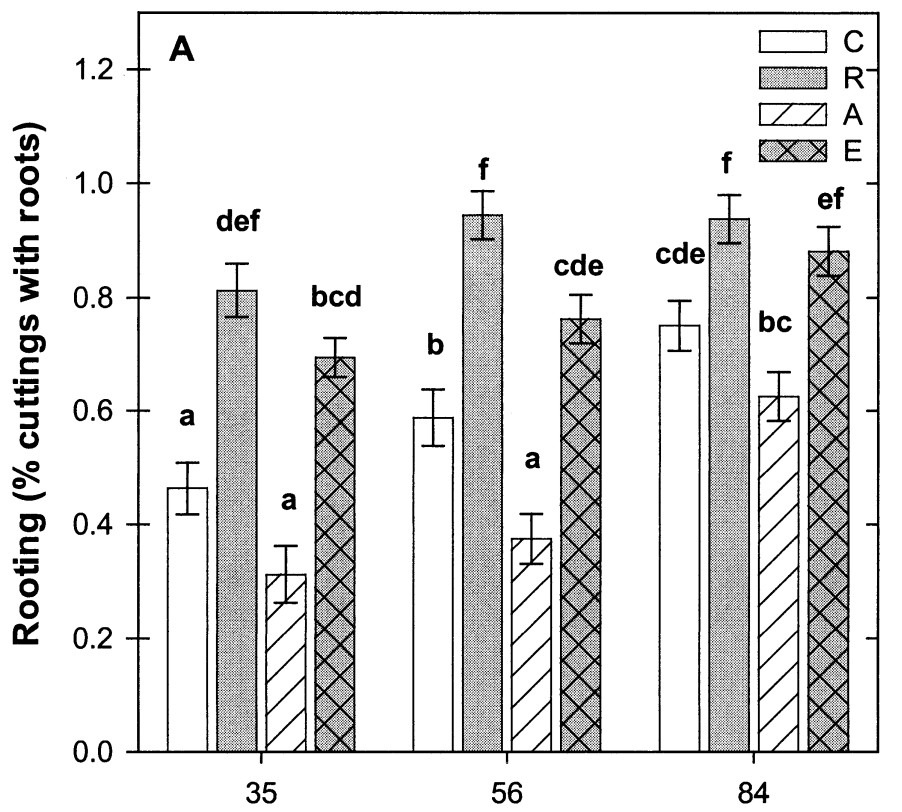

Time after sticking (d)

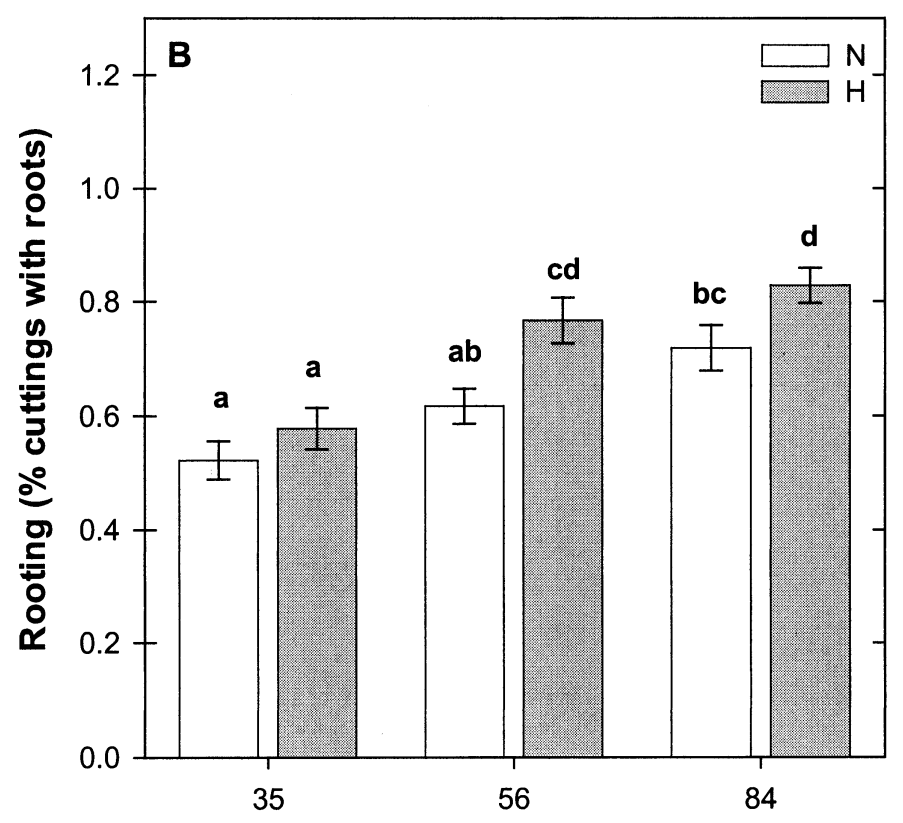

Time after sticking (d)

Fig. 1. Influence of mycorrhizal inoculation (A) and root hormone (B) treatments on the percentage of kinnikinnick 'Massachusetts'cuttings with roots 35, 56, and $84 \mathrm{~d}$ after sticking. Mycorrhizal inoculation treatments: $\mathrm{C}=$ no inoculum; $\mathrm{R}=$ root inoculum; $\mathrm{A}=$ arbuscular mycorrhizal fungal inoculum; and $\mathrm{E}=$ arbutoid mycorrhizal fungal inoculum in rooting substrate. Rooting hormone treatments: $\mathrm{N}=$ no rooting hormone; $\mathrm{H}=$ rooting hormone applied to cutting. Bars on data points represent standard errors $(n=8)$. Columns with the same letter above them are not significantly different (Bonferroni test, $P>0.05$ ).

may activate the fungal spores and/or hyphae (Tamasloukhtetal., 2003). The fungus may release fungal metabolites that induce plant metabolic changes (Larose et al., 2002), thereby increasing rooting on cuttings inoculated with AMF. However, if the signals from the fungus are not compatible with the host plant, increased rooting of cuttings may not occur.

Using AMF inoculum in the rooting substrate does not appear to be an effective strategy for increasing rooting of kinnikinnick. The ability of arbutoid 
mycorrhizal fungi to increase rooting during cutting propagation of kinnikinnick may primarily be of benefit to growers by decreasing the production time for cuttings to grow an adequate amount of roots for transplanting. Since there appears to be no difference in rooting between cuttings inoculated with root fragments and arbutoid mycorrhizal fungal hyphae, it is probably safer to inoculate with known fungal inoculum than root fragments due to the potential danger of transferring pathogens into the propagation system by using root fragments.

RoOT INITIATION. The number of primary roots on cuttings at the first harvest, $35 \mathrm{~d}$ after sticking, was not influenced by either inoculation (Fig. $2 \mathrm{~A})$ or rooting hormone treatment (Fig. 2B). At the later harvests 56 and $84 \mathrm{~d}$ after sticking cuttings inoculated with either the $\mathrm{R}$ or $\mathrm{E}$ inoculum had more primary roots than non-inoculated cuttings. Inoculation with AMF had no influence on root initiation.

There is conflicting information on the influence of mycorrhizal fungi on root initiation during adventitious rooting of cuttings. Verkade and Hamilton (1987) found that the presence of the AMF, Glomus fasciculatum, in the rooting substrate increased root development and growth of arrowwood (Viburnum dentatum) but not root initiation. Scagel (2001) found that adding Glomus intraradices inoculum into the rooting substrate of miniature roses did not always increase root initiation, but in some miniature rose cultivars, the combination of AMF inoculum and rooting hormone increased root initiation. Scagel (2003) found that adding Glomusintraradices inoculum to the rooting substrate of hick's yew (Taxus $\times$ media 'Hicksii') increased root initiation, although response was dependent on the quantity of inoculum in the rooting substrate.

The differences we observed in root initiation between kinnikinnick cuttings inoculated with root fragments and those inoculated with hyphae could have been due to a relationship between inoculum level and rooting response. The inoculum potential of the inoculum made of root fragments was not determined due to the non-sterile nature of the inoculum and the inability to separate out the arbutoid fungi in the roots from other rhizosphere organisms

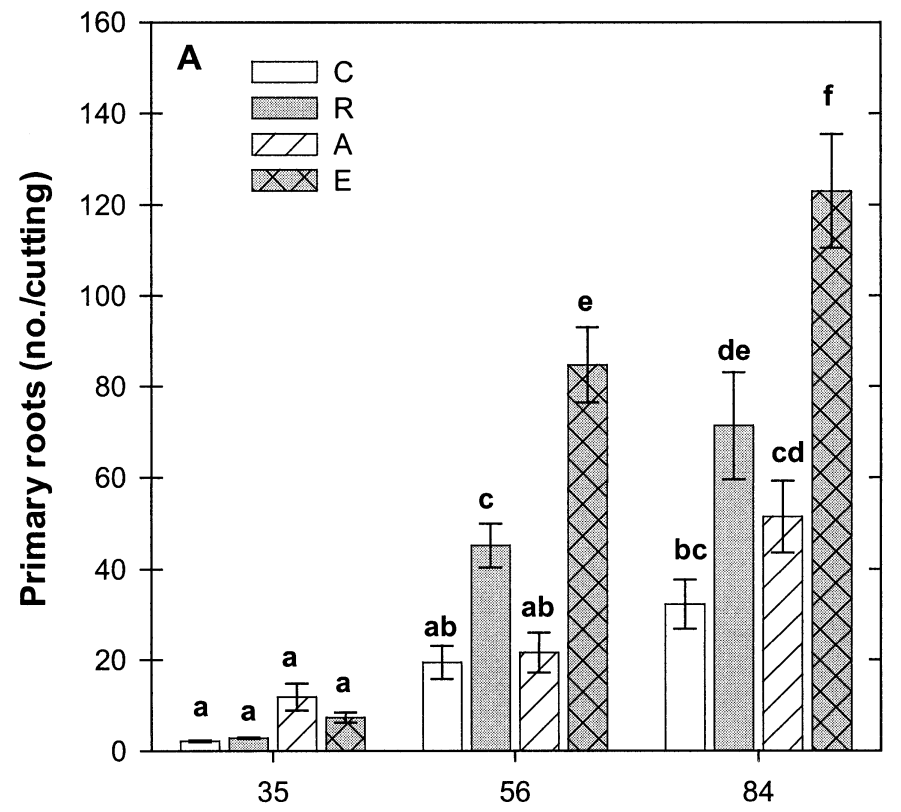

Time after sticking (d)

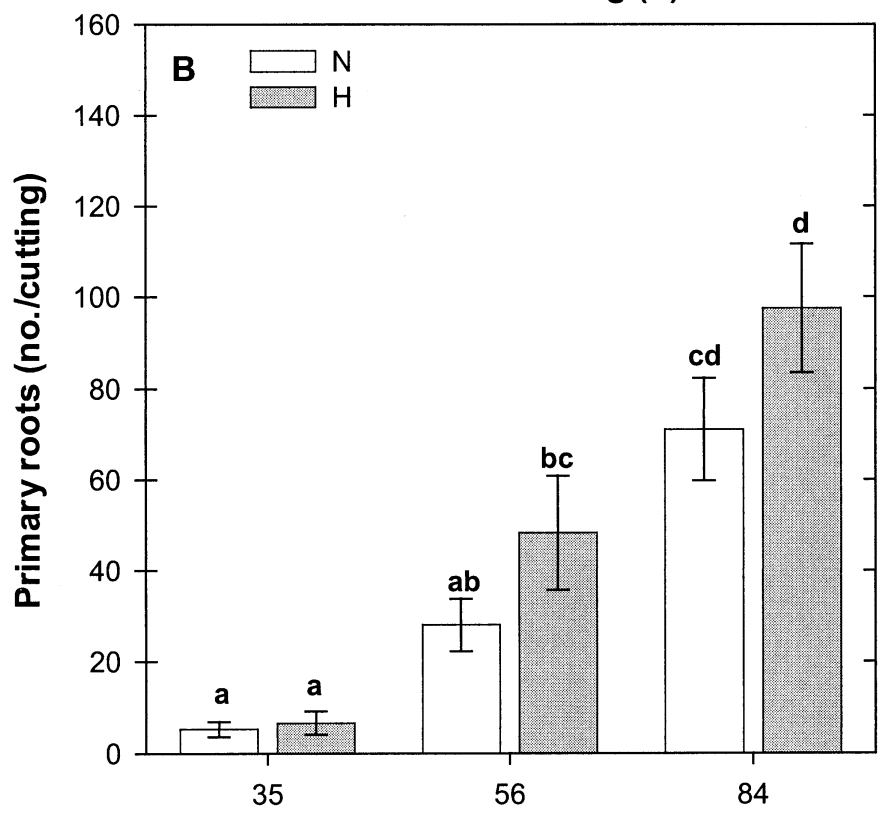

Time after sticking (d)

Fig. 2. Influence of mycorrhizal inoculation (A) and rooting hormone (B) treatments on the number of primary on kinnikinnick 'Massachusetts' cuttings 35, 56 , and $84 \mathrm{~d}$ after sticking. Mycorrhizal inoculation treatments: $\mathrm{C}=$ no inocu$\operatorname{lum} ; \mathrm{R}=$ root inoculum; $\mathrm{A}=$ arbuscular mycorrhizal fungal inoculum; and $\mathrm{E}=$ arbutoid fungal mycorrhizal inoculum in rooting substrate. Rooting hormone treatments: $\mathrm{N}=$ no rooting hormone; $\mathrm{H}=$ rooting hormone applied to cutting. Bars on data points represent standard errors $(n=8)$. Columns with the same letter above them are not significantly different (Bonferroni test, $P>0.05$ ).

in culture. Another potential reason a different amount of root initiation was observed on kinnikinnick cuttings inoculated with root fragments and those inoculated with hyphae could have been due to a type of fungal-plant specificity similar to that reported for rainbow leucothoe (Scagel, 2004b). Cuttings of rainbow leucothoe had greater root initiation when inoculated with ericoid mycorrhizal fungi than non-inoculated cuttings; however increased initiation was only observed with two of the three isolates tested. 
The fungi associated with the roots of the kinnikinnick plants used to make the root inoculum may not have been the same isolate as the fungus used for the hyphal inoculum, so differences in response to the different inoculum types may be solely a result of the different fungal isolates.

RoOT BRANCHING. The average number of secondary roots per primary root was used to assess the degree of root branching on cuttings. At the first harvest, $35 \mathrm{~d}$ after sticking, neither inoculation nor rooting hormone treatments influenced root branching on cuttings (Fig. 3A-B). At the second harvest, $56 \mathrm{~d}$ after sticking, roots on cuttings inoculated with either the R or E inoculum were more branched than roots on non-inoculated cuttings, and roots on cuttings treated with rooting hormones were more branched than roots on cuttings not treated with hormones. At the end of the experiment, the amount of root branching on cuttings was similar across inoculation treatments, while roots on cuttings that received rooting hormone were more branched than roots on cuttings that received no rooting hormone.

The growth and development of roots after initiation can influence the length of a production cycle and the quality of the cutting produced during propagation. When cuttings of rainbow leucothoe were inoculated with ericoid mycorrhizal fungi, their roots were generally less branched than the roots on non-inoculated cuttings (Scagel, $2004 b$ ). However, the morphology of kinnickinnick roots is more complex than the single cortex layer found in roots of ericoid mycorrhizal plants. Kinnickinnick roots generally exhibit dichotomous branching or multiple root proliferation in a restricted root length when colonized by mycorrhizal fungi, and non-colonized roots tend to have longer distances between second-order roots. Roots of ericoid mycorrhizal plants do not show a similar pattern of root development and morphology. The distance between second order lateral roots on kinnickinnick cuttings were not measured in this study. However, since cuttings that received rooting hormone also showed a time-dependent increase in root branching, it is possible that the response of root branching to inoculation with the $\mathrm{E}$ or R inoculum may be related to hormone-mediated changes in plant metabolism. Auxins are re-

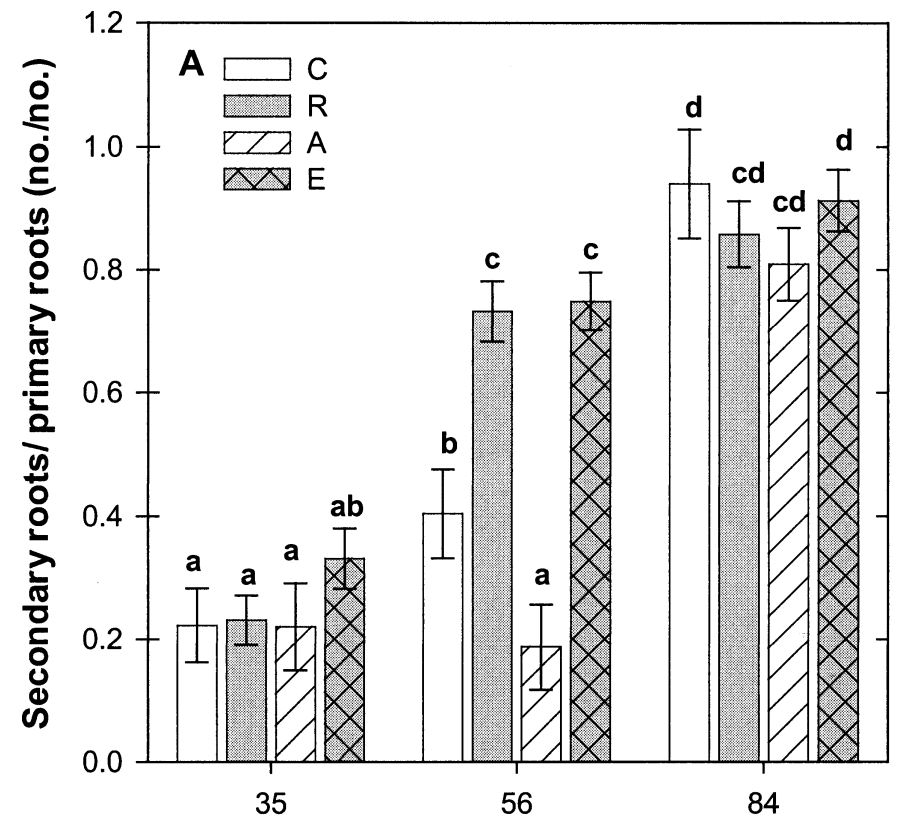

Time after sticking (d)

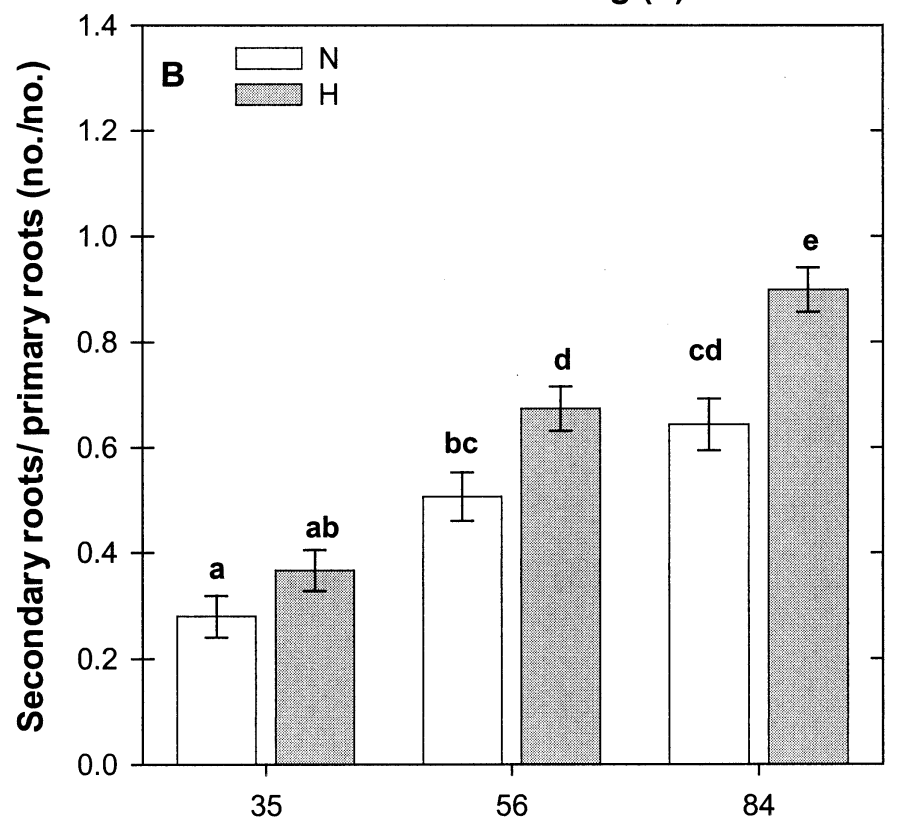

Time after sticking (d)

Fig. 3. Influence of mycorrhizal inoculation (A) and rooting hormone (B) treatments on the branching of roots on kinnikinnick 'Massachusetts' cuttings 35, 56, and $84 \mathrm{~d}$ after sticking. Mycorrhizal inoculation treatments: $\mathrm{C}=$ no inoculum; $\mathrm{R}$ $=\operatorname{root}$ inoculum; $\mathrm{A}=$ arbuscular mycorrhizal fungal inoculum; and $\mathrm{E}=$ arbutoid mycorrhizal fungal inoculum in rooting substrate. Rooting hormone treatments: $\mathrm{N}=$ no rooting hormone; $\mathrm{H}=$ rooting hormone applied to cutting. Bars on data points represent standard errors $(n=8)$. Columns with the same letter above them are not significantly different (Bonferroni test, $P>0.05$ ).

ported to induce branching in roots (Biondi et al., 1997). Ectomycorrhizal fungi have been found to produce auxins and other hormones and induce changes in root hormone levels during adventitious root formation (Niemi et al., 2002, 2004). It is possible that the fungi in the $\mathrm{R}$ and $\mathrm{E}$ inoculum may produce hormones or induce plant production of hormones that cause stimulation of root development via similar mechanisms that result from application of rooting hormone. The pattern we observed in root branching 
Fig. 4. Length and weight of roots on kinnikinnick 'Massachusetts' cuttings $35(\mathrm{~A}), 56(\mathrm{~B})$, and $84(\mathrm{C}) \mathrm{d}$ after sticking and rooting hormone and mycorrhizal inoculation treatments. Mycorrhizal inoculation treatments: $\mathrm{C}=$ no inoculum; $\mathrm{R}=$ root inoculum; $\mathrm{A}=$ arbuscular mycorrhizal fungal inoculum; and $\mathrm{E}$ $=$ arbutoid mycorrhizal fungal inoculum in rooting substrate. Rooting hormone treatments: $\mathrm{N}=$ no rooting hormone; $\mathrm{H}=$ rooting hormone applied to cutting. Bars on data points represent least significant differences (Bonferroni test, $P>0.05)(2.54$ $\mathrm{cm}=1.0$ inch; $28,350 \mathrm{mg}=1 \mathrm{oz})$.

of kinnikinnick cuttings in response to inoculation with AMF may also be a plant hormonal response, but instead of a compatibility signal between the plant and fungus, an incompatibility signal may trigger a delay in root branching. Without colonization occurring, subsequent root branching is increased and root growth proceeds as with non-inoculated cuttings.

ROOT SIZE AND MORPHOLOGY. Rooting hormone had no effect on the length or weight of roots on non-inoculated cuttings or cuttings inoculated with AMF $35 \mathrm{~d}$ after sticking, while rooting hormone increased the length and weight of roots on cuttings inoculated with the $\mathrm{R}$ or E inoculum (Fig. 4A). At the later harvests, 56 and $84 \mathrm{~d}$ after sticking, cuttings inoculated with the $\mathrm{E}$ and Rinoculum had longer roots than non-inoculated cuttings but only when treated with rooting hormone (Fig. 4B-C). Only cuttings inoculated with the E inoculum had a greater total root biomass than non-inoculated cuttings at the later harvests. Cuttings inoculated with AMF had slightly longer roots than non-inoculated cuttings, but only if cuttings were also treated with rooting hormone.

Specific root length (root length divided by root weight) can be used to assess root morphology; lower values denote coarser or denser roots compared to higher values representing thinner or less-dense roots. Inoculation treatments had no influence on specific root length $35 \mathrm{~d}$ after cuttings were stuck (Table 1). At the later harvests, inoculated cuttings generally had higher specific root length than non-inoculated cuttings, but only on cuttings to which hormone had been applied. In general, rooting hormone application had no influence on specific root length of inoculated cuttings, but decreased specific root length of noninoculated cuttings. Specific root length on cuttings increased over time and the change in specific root length over time was greater when cuttings were treated with hormone and inoculated with any of the mycorrhizal inocula.

Depending on the length of time after sticking, cuttings of rainbow leucothoe inoculated with ericoid mycorrhizal fungi generally had a greater total weight and length of roots than non-inoculated cuttings; however, while the specific root length of inoculated and non-inoculated cuttings were similar by the end of the experiment, roots on inoculated cuttings generally became coarser or attained a greater root mass density more quickly than roots on non-inoculated cuttings (Scagel, 2004b). This indicates that the ericoid mycorrhizal fungi had little influence on the gross morphology of individual roots of rainbow leucothoe but did alter the timing of root development. With kinnikinnick, we observed an opposite trend in specific root length with addition of mycorrhizal inoculum into the rooting substrate. When cuttings were treated with hormones, roots on inoculated cuttings were finer than non-inoculated cuttings, however although hormone application decreased specific root length of non-inoculated cuttings, it had no influence on specific root length of inoculated cuttings. This suggests that even though arbutoid mycorrhizal fungi may influence root development
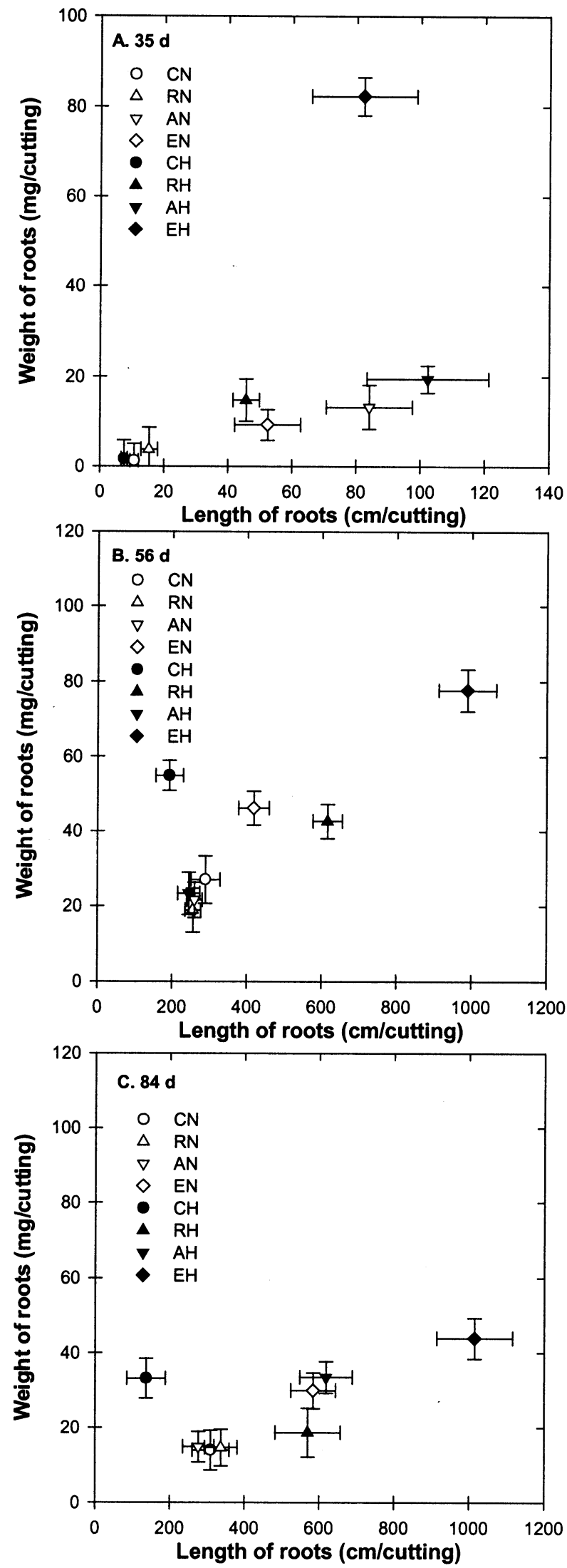
via mechanisms similar to that induced by application of rooting hormone, the mechanism via which the mycorrhizal fungus influences the morphology of kinnikinnick roots may be different. Comas et al. (2002) suggest that plants with higher specific root length have a higher maintenance cost due to respiratory losses. During cutting propagation, high respiration rates without adequate replenishment of energy from photosynthesis can decrease the quality of cuttings (Friend et al., 1994). It is possible that the shift we observed in differences in specific root length between inoculated and non-inoculated cuttings is a result of the maintenance costs required to establish the fungus-plant symbiosis.

With miniature roses, cuttings treated with the combination of rooting hormone and Glomusintraradicesinoculum had greater root weight when compared to cuttings from other treatments, while roots on cuttings treated with rooting hormone were generally smaller (shorter and/or thinner) than roots on cuttings from untreated controls (Scagel, 2001). In that study, cuttings from miniature rose cultivars with G. intraradices inoculum in the rooting substrate had similar root size when compared to cuttings from untreated controls. Since root length and diameter were not measured in this study, it is impossible to state whether these smaller roots were shorter or thinner or whether larger roots were thicker or longer. However, this alteration in root size and anatomy induced by inoculation of cuttings with mycorrhizal fungi appears to be time-dependent and may influence the function of the new root system relative to water use, nutrient uptake, as well as survival during transplanting.

MyCORRHIZAL COLONIZATION. Roots on non-inoculated cuttings and cuttings inoculated with AMF showed no signs of colonization by mycorrhizal fungi during the experiment. At the first harvest, $35 \mathrm{~d}$ after sticking, less than $10 \%$ of the root tips on cuttings inoculated with either the $\mathrm{E}$ or R inoculum were colonized (Fig. 5). At later harvest dates, root colonization was similar or greater when cuttings were inoculated with the $\mathrm{E}$ inoculum than with the $\mathrm{R}$ inoculum, and application of rooting hormone generally increased root colonization. At the first harvest, root colonization on cuttings inoculated with either the $\mathrm{R}$ or $\mathrm{E}$ inoculum was not correlated with any root growth variables. At the second harvest root colonization on cuttings inoculated with the $\mathrm{R}$ inoculum was positively correlated with root length $(r=0.61)$ and colonization on cuttings inoculated with the $\mathrm{E}$ inoculum was positively correlated with the number of primary roots $(\mathrm{r}=0.54)$ and root length $(\mathrm{r}=0.62)$. At the final harvest, the number of primary roots and root length on cuttings inoculated with either the $\mathrm{R}$ or $\mathrm{E}$ inoculum was correlated with the number of primary roots $(\mathrm{r}=0.57)$ and root length $(\mathrm{r}=0.63)$.

Colonization of roots by mycorrhizal fungi can increase the survival and growth of plants. Depending on the amount of time after sticking, root colonization of rainbow leucothoe cuttings by ericoid mycorrhizal fungi was correlated with root initiation, root growth and morphology (Scagel, 2004b). Verkade and Hamilton (1981) found that

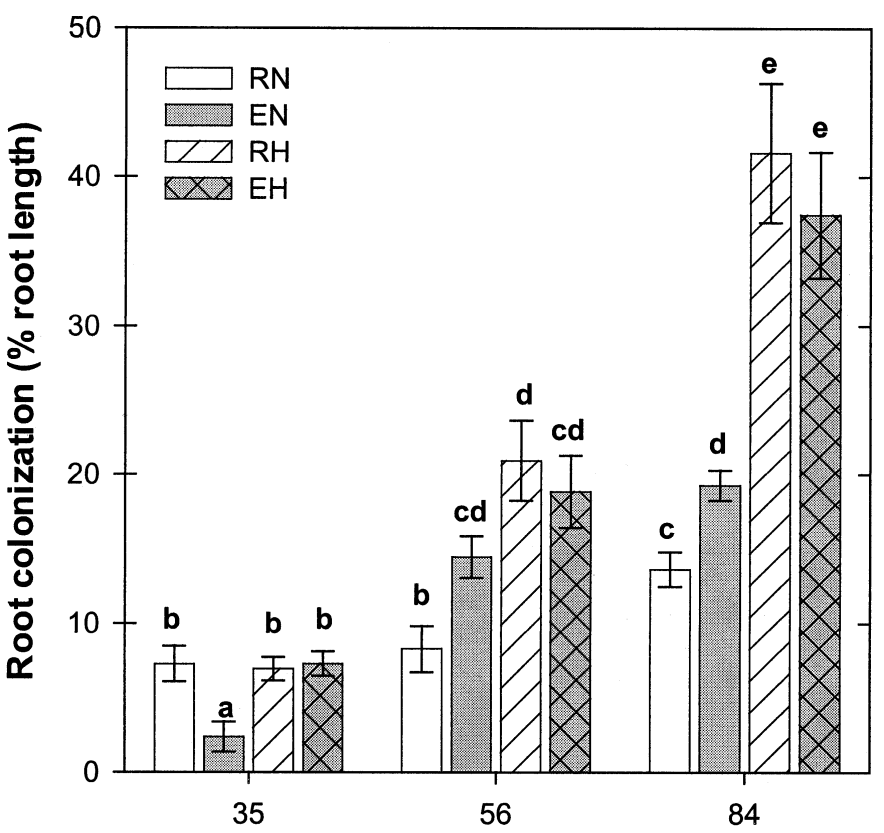

Time after sticking (d)

Fig. 5. Root colonization of kinnikinnick 'Massachusetts' cuttings 35,56 , and $84 \mathrm{~d}$ after sticking and rooting hormone and mycorrhizal inoculation treatments. First letter of treatment acronym: $\mathrm{R}=$ root inoculum; and $\mathrm{E}=$ arbutoid mycorrhizal fungal inoculum in rooting substrate. Second letter of treatment acronym: $\mathrm{N}=$ no rooting hormone; $\mathrm{H}=$ rooting hormone applied to cutting. Bars on columns represent standard errors $(n=8)$. Columns with the same letter above them are not significantly different (Bonferroni test, $P>0.05)$. None of the cutting from control $(\mathrm{CN}$ and $\mathrm{CH})$ or $\mathrm{AN}$ or $\mathrm{AH}$ inoculation treatments were colonized.

extensive mycorrhizal development occurred on roots of regal privet (Ligustrum obtusifolium var. regelianum) after 6 weeks of rooting in a substrate inoculated with Glomus mosseae. Mycorrhizal colonization coincided with substantially increased root development, but no effects on root initiation were found. Scagel (2001) reported that increases in root initiation and root growth of miniature rose cuttings rooted in substrate containing the AMF G. intraradices were not 
always associated with increased levels of colonization. Scagel (2003) also reported that the number of roots, root weight, and stem weight of hick's yew were significantly correlated with colonization with AMF. However, increased root initiation of hick's yew cuttings rooted in substrate containing AMF inoculum were not always associated with increased levels of colonization. Verkade et al. (1988) observed that inoculation of red-osier dogwood (Cornus sericea) cuttings with the AMF, Glomus fasciulatum, substantially increased plant growth during later stages of cutting development. In comparison, inoculated seedlings of red-osier dogwood had lower root colonization and similar growth as non-inoculated seedlings. In soilless substrates lacking indigenous mycorrhizal fungi, mycorrhizal inoculation has been found to increase crop uniformity, reduce transplant mortality, and increase productivity of several plant species (Biermann and Linderman, 1983; Powell and Bagyaraj, 1984; Vosátka, 1995; Vosátka et al., 1999). In our experiment, although inoculation with arbutoid mycorrhizal fungi did not consistently increase rooting and root growth, the root colonization resulting from inoculation could result in a higher quality of cutting that is better able to withstand the stress of transplanting and increase growth during the later stages of plant development.

\section{Conclusions}

Using arbuscular mycorrhizal fungus inoculum in the rooting substrate does not appear to be an effective strategy for increasing rooting or root growth of kinnikinnick cuttings. Addition of inoculum of arbutoid mycorrhizal fungi into the rooting substrate either as root fragments or hyphae can enhance early rooting of cuttings. Inoculation can increase root growth when cuttings are treated with rooting hormone. Since kinnickinnick cuttings responded similarly to inoculum composed of either colonized root fragments or arbutoid fungal hyphae, using a hyphal inoculum of a know species of arbutoid mycorrhizal fungi may be a better propagation practice due to reduced potential for transfer of deleterious organisms to the propagation substrate.

\section{Literature cited}

Biermann, B. and R.G. Linderman. 1980. Quantifying vesicular-arbuscular mycorrhizae: A proposed method towards standardization. New Phytol. 87:63-67.

Biermann, B. and R.G. Linderman. 1983. Increased geranium growth using pretransplant inoculation with a mycorrhizal fungus. J. Amer. Soc. Hort. Sci. 108:972-976.

Biondi, S., C. Lenzi, R. Baraldi, and N. Bagni. 1997. Hormonal effects on growth and morphology of normal and hairy roots of Hyoscyamus muticus. J. Plant Growth Regulat. 16:159-167.

Chang, D.C. 1994. What is the potential for management of vesicular-arbuscular mycorrhizae in horticulture? p. 87-90. In: A.D. Robson, L.K. Abbot, and N. Malajczuk (eds.). Management of mycorrhizas in agriculture, horticulture, and forestry. Kluwer Acad. Publ., Dordrecht, The Netherlands.

Comas, L.H., T.J. Bouma, and D.M. Eissenstat. 2002. Linking root traits to potential growth rate in six temperate tree species. Oecologia 132:34-43

Douds, D.D., G. Becard, P.E. Pfeffer, L.W. Doner, T.J. Dymant, and W.M. Kayer. 1995. Effect of vesicular-arbuscular mycorrhizal fungi on rooting of Sciadopitysverticillata Sieb \& Zucc. cuttings. HortScience 30:133-134.

Friend, A.L., M.D. Coleman, and J.G. Isebrands. 1994. Carbon allocation to root and shoot systems of woody plants, p. 245-273. In: T.D. Davis and B.E. Haissig (eds.). Biology of adventitious root formation. Plenum Press, New York.

Górecka, K. 1979. The effect of growth regulators on rooting of ericaceae plants. Acta Hort. 91:483-490.

Holden, V.F. 1975. Propagation of Arctostaphylos uva-ursi by cuttings. Combined Proc. Intl. Plant Prop. Soc. 25:74-77.

Holden, V.L. 1978. The use of mycorrhizae in the propagation of Arctostaphylosuva-ursi. Combined Proc. Intl. Plant Prop. Soc. 28:132-133.

Larose, G., R. Chenevert, P. Moutoglis, S. Gagne, Y. Piche, and H. Vierheilig. 2002. Flavonoid levels in roots of Medicago sativa are modulated by the developmental stage of the symbiosis and the root colonizing arbuscular mycorrhizal fungus. J. Plant Physiol. 159:1329-1339.

Linderman, R.G. and C.A. Call. 1977. Enhanced rooting of woody plant cuttings by mycorrhizal fungi. J. Amer. Soc. Hort. Sci. 102:629-632.

Molina, R. and P.G. Palmer. 1982. Isolation, maintenance, and pure culture manipulation of ectomycorrhizal fungi, p. 115-129. In: N.C. Schenck (ed.). Methods and principles of mycorrhizal research. Amer. Phytopathol. Soc., St. Paul, Minn.

Niemi, K., T. Vuorinen, A. Ernsten, and H. Häggman. 2002. Ectomycorrhizal fungi and exogenous auxins influence root and mycorrhiza formation of Scots pine hypocotyl cuttings in vitro. Tree Physiol. 22:1231-1239.

Niemi, K., C. Scagel, and H. Häggman. 2004. Application of ectomycorrhizal fungi in vegetative propagation of conifers. Plant Cell Tissue Organ Cult. 78:83-91.

Nelson, S.D. 1987. Rooting and subsequent growth of woody ornamental softwood cuttings treated with endomycorrhizal inoculum. J. Amer. Soc. Hort. Sci. 112:263-266.

Phillips, J.M. and D.S. Hayman. 1970. Improved procedures for clearing roots and staining parasitic and vesicular-arbuscular mycorrhizal fungi for rapid assessment of infection. Trans. Brit. Mycol. Soc. 55:158-160.

Powell, C.L. and D.J. Bagyaraj. 1984. Effect of mycorrhizal inoculation on the production of blueberry cuttings-A note. N.Z. J. Agr. Res. 27:467-471.

Roussel, H., D. van Tuinen, P. Franken, S. Gianinazii, and V. Gianinazzi-Pearson. 2001. Signaling between arbuscular mycorrhizal fungi and plants: Identification of a gene expressed during early interactions by differential RNA display analysis. Plant Soil 232:13-19.

Scagel, C.F. 2000. Using mycorrhizal fungi during propagation of woody horticultural crops. Combined Proc. Intl. Plant Prop. Soc. 50: 589-594.

Scagel, C.F. 2001. Cultivar specific effects of mycorrhizal fungi on the rooting of miniature rose cuttings. J. Environ. Hort. 19:15-20.

Scagel, C.F. 2003. Mycorrhizal fungi in rooting substrate influences the quantity and quality of roots on stem cuttings of hick's yew. Hort Techology 13:62-66.

Scagel, C.F. 2004a. Influence of arbuscular mycorrhizal inoculum on cutting composition during early stages of adventitious rooting in miniature rose. J. Amer. Soc. Hort. Sci. (In press.)

Scagel, C.F. 2004b. Isolate-specific rooting responses of Leucothoe fontanesiana cuttings to inoculation with ericoid mycorrhizal fungi. J. Hort. Sci. Biotechnol. (In press.)

Smith, S.E. and D.J. Read, D. J. 1997. Mycorrhizal symbiosis. Acad. Press., San Diego.

Tamasloukht, M’B., N. Séjalon-Delmas, A. Kluever, A. Jaunean, C. Roux, G. Bécard, and P. Franken. 2003. Root factors induce mitochondrial-related gene expression and fungal respiration during the developmental switch from asymbiosis to presymbiosis in the arbuscular mycorrhizal fungus Gigaspora rosea. Plant Physiol. 131:1468-1478.

Verkade, S.D. and D.F. Hamilton. 1981. Mycorrhizae and their uses in the nursery. Combined Proc. Intl. Plant Prop. Soc. 30:353-362.

Verkade, S.D. and D.F. Hamilton. 1987. Effect of endomycorrhizal inoculum on root initiation and development of Viburnum dentatum L. cuttings. J. Environ. Hort. 5:80-81.

Verkade, S.D., L.C. Elson, and D.F. Hamilton. 1988. Effect of endomycorrhizal inoculation during propagation on growth following transplanting of Cornussericea cuttings and seedlings. Acta Hort. 227:248-250.

Vosátka, M. 1995. Influence of inoculation with arbuscular mycorrhizal fungi on the growth and mycorrhizal infection of transplanted onion. Agr. Ecosystem Environ. 53:151-159.

Vosátka, M., J. Jansa, M. Regvar, F. Sramek, and R. Malcova. 1999. Inoculation with mycorrhizal fungi-A feasible biotechnology for horticulture. Phyton. 39:219-244.

Woomer, P.L. 1994. Most probable number counts, p. 59-79. In: R.W. Weaver (ed.). Methods of soil analysis, Part 2. Soil Sci. Soc. Amer., Madison, Wis. 